\title{
The Moral Metaphysics of Causation and Results
}

\author{
Stephen J. Morse $†$
}

\section{INTRODUCTION}

Causation matters in criminal law only because results do. My colleague and friend, Michael Moore, firmly believes that wrongdoing-by which he means the amount of harm an agent actually causes by intentional conduct-independently contributes to an offender's moral desert, but actual harm is not necessary to desert. ${ }^{1}$ Wrongdoing is "something of [a] poor relation" to culpability, as Michael puts it, but it nonetheless contributes independently to desert and thus it is crucial to identify which wrongs a defendant caused. ${ }^{2}$ In The Metaphysics of Causal Intervention, Michael questions "whether the intervening-cause notions of the law can be based on a prelegal notion of causation, one that provides a solid grounding for the sharp breaks in causal chams so marked by the law." ${ }^{3}$ Michael's analysis addresses causal doctrine in both tort and criminal law, but I shall focus solely on criminal law because virtually all criminal law theorists agree that moral fault is at least a necessary condition of blame and punishment, whereas torts theorists famously disagree about whether blame has any place in a scheme of tort liability. I shall also draw freely from Michael's earlier work on causation, which his present Essay extends, because it is imipossible to understand Michael's current quest without referring to earlier parts of the journey.

Copyright $\odot 2000$ California Law Review, Inc. California Law Review, Incorporated (CLR) is a California nonprofit corporation. CLR and the authors are solely responsible for the content of their publications.

$\dagger \quad$ Ferdinand Wakeman Hubbell Professor of Law and Professor of Psychology and Law in Psychiatry, University of Pennsylvania. This Response was prepared while the author was William Minor Lile Visiting Professor of Law at the University of Virginia. It was first presented at a conference, The Morality of Criminal Law: A Symposium in Honor of Professor Sandy Kadish. I should like to thank Michael Moore and all the other conference partieipants for lielpful comments. Stephen Perry provided valuable insights.

1. See Michael S. Moore, Placing Blame: A Theory of the Criminal Law 191-93 (1997).

2. Id. at 193 .

3. Michael S. Moore, The Metaphysics of Causal Intervention, 88 CALIF. L. REv. 827, 828 (2000). 
The first major Part of Michael's Essay attempts a rational reconstruction of the law's doctrines of intervening causation; the second begins the daunting task of discovering a metaphysical rationale for the law's causation doctrines, including an analysis of why libertarian metaphysics cannot provide that rationale. The basic thesis is that legal causation doctrine is best morally justified if it reflects the actual metaphysics of causation and that it is possible to demonstrate that it does so. The Essay is a classic Moore effort: immensely dense but utterly clear; carefully and relentlessly argued; uniformly interesting. One could quibble with either half of the Essay, but I am in awe of and applaud both the breathtaking, bravura reconstruction of present doctrines and the analysis of the metaphysics of causation. Despite the customary intellectual pyrotechnics, however, Michael ends the Essay uncharacteristically. Instead of concluding from the distinctive torrent of arguments that his thesis is correct, Michael modestly recogmizes that the task is unfinished and that perhaps the approach adopted is not fully promising. I believe that he is right to recognize that the work to defend his thesis is not complete, but I also think that it cannot be completed.

This Response provides an external critique of Michael's Essay. Rather than dispute either half, I suggest instead that the project is problematic in conception. In particular, I propose that any desert-based attempt to justify legal causation doctrine by a prelegal metaphysics of causation is bound to fail for two reasons. Part I of this Response explores the first: Results do not matter to desert according to any plausible theory of the relation between determinism or mechanism and responsibility, and therefore neither does causation. No true metaphysical rationale is likely to underpin a rationally indefensible set of doctrines, even if an apparently logical or commonsensical structure for those doctrines can be constructed ex post by people as talented as Herbert Hart, Tony Honoré, ${ }^{4}$ and Michael Moore. ${ }^{5}$ Part II of this Response addresses the second reason why a desertbased, metaphysical justification for legal causation doctrine will fail: Even if results do matter, the legal doctrines of causation are unlikely to map dependably the prelegal metaphysics of causation, that is, the universe's ontology of physical cause and effect. It is metaphysically implausible that there are "sharp breaks" in the "causal chains" of the universe that would provide a moral rationale for the same sharp breaks in legal doctrine that Michael accurately identifies. Moreover, the rampant and unavoidable complexity and vagueness of causation doctrine, which was

4. See H.L.A. Hart \& TONy Honore, Causation in the Law (2d ed. 1985); Tony Honoré, RESPONSIBILITY AND FAULT (1999).

5. See Miehael S. Moore, Causation, in 1 Encyclopedia of Crime and Justrce (Joshua Dressler et al. eds., rev. ed. forthcoming 2000); Michael S. Moore, Causation and Responsibility, Soc. PHIL. \& Pol'y, Summer 1999, at 1. 
created to solve legal liability problems, not to specify the metaphysics of actual physical causation, also suggest that the map is unlikely to prove a useful guide.

\section{I}

\section{Results and Causation Do Not Matter to Desert}

Let us begin with a brief consideration of the standard analysis of why results and therefore causation do not matter, to which I will add my own analysis. As Sandy Kadish has so compellingly demonstrated, the criminal law's emphasis on results is not rationally defensible on either a theory of crime prevention or moral desert. ${ }^{6}$ The miscreant who acts intentionally and either intends or risks harm is equally dangerous and culpable, whether or not the intended or risked harm actually occurs. The criminal law prohibits dangerous action culpably performed, not harmful results. Unlike the defendant's actions, which are under his or her control, results are allegedly not under the defendant's control and are just a matter of so-called moral luck. ${ }^{7}$ Therefore, results do not matter, and causation should not either. Although I am entirely in sympathy with this argument, more needs to be said about moral luck and the alleged distinction between human action and results.

As Michael has argued, and I agree, the problem of moral luck goes all the way down to the turtle's back; in other words, there is no problem of moral luck. ${ }^{8}$ Indeed, the so-called problems of moral luck are simply redescriptions of the questions determinism or mechanism raises for responsibility generally. In a deterministic or universally caused world of mechanism, the causal antecedents to actions, actions themselves, and the results of actions are all the products of the causal laws of the universe operating on prior events. As a product of causation, there is nothing distinctive about the luck of results. For perfectly explicable causal reasons, the causal forces of the universe either do or do not produce the harms a malefactor intends or risks. And for similarly explicable causal reasons, we have the types of characters that we do, we have the opportunities that we do, and we intentionally act as we do. No one is a prime mover unmoved, a being with contra-causal freedom that can rival or override the world of causes that we inhabit. Put yet another way, moral and legal responsibility cannot depend on "luck" because there is no such thing as luck, or if there is such a thing, it applies to everything, including character, opportunity, actions, and results.

6. See Sanford H. Kadish, Foreword: The Criminal Law and the Luck of the Draw, 84 J. CRIM. L. \& CRIMINology 679 (1994) (arguing also that perhaps the emphasis on results is too ingrained in our total moral outlook to permit abandoning it in criminal law).

7. See id. at 689-90.

8. See MOORE, supra note 1 , at $233-46$. 
Those, including myself, who claim that results do not matter to desert cannot simply say that human action by rational adults is freely chosen and uncaused, whereas results are potentially caused by variables the agent has not intended and cannot possibly control. A more detailed answer is necessary. If the problem of moral luck has been dissolved-if mechanism or determinism is true and if everything is a matter of luck-does this mean that no one is really responsible for anything, including both wrongful actions and results? And if responsibility can be salvaged in an entirely causal world, can action and results be distinguished for the purpose of ascribing responsibility and desert?

There are two standard approaches to considering whether moral responsibility is possible in a fully caused universe. The first is "incompatibilism," which comes in two forms, hard determinism and libertarianism. The former admits that mechanism is true and claims that no one is responsible for anything. The latter denies that mechanism is true, especially as an explanation of human action. The second approach, "compatibilism," also embraces mechanism but claims that responsibility is nonetheless possible. I will consider the two answers in order. I suggest briefly that hard determimsm can neither explain our practices nor ground a theory of desert. It may guide a consequentialist view of how results should be treated, but it cannot justify why results should or should not matter to desert, and it surely need not map the actual metaphysics of causation. Libertarianism seems to suggest that results do not matter because human action is uncaused and not a matter of luck, whereas results are caused by variables the agent cannot control and therefore are a product of luck. Although it is always comforting to have allies in my claim that results do not matter, I conclude in agreement with Michael that libertarianism makes little sense and, consequently, cannot guide any sensible legal policy. Then I shall argue that compatibilism, which provides both the best positive and normative account of our responsibility practices, is inconsistent with the view that results should matter.

\section{A. Incompatibilism}

Let us begm with hard determinism, which claims that determinism is true and that no one is really responsible, but for good consequential reasons, the criminal law behaves "as if" people were responsible.' Thus, if treating results as if they matter increases the likelihood of good behavior and decreases the likelihood of bad, results should matter, whether or not they have anything to do with real responsibility. Correlatively, we should adopt those doctrines of legal causation that would most encourage beneficial outcomes, whether or not those doctrines are congruent with the

9. See Daniel C. Dennett, Elbow Room: The Varieties of Free Will Worth Wanting 156-65 (1984); Herbert L. PACKer, The Limits of the Criminal SANCTiOn 74-75 (1968). 
genuine metaphysics of causation and whether or not they have anything to do with real responsibility. There is no a priori reason to believe that those legal causation doctrines that will decrease the risk of harmdoing in fact track the metaphysics of causation. Reductionistic consequentialism is of course internally logical. Treating people as responsible by blaming and punishing them as if they really were may indeed discourage wrongdoing in various ways. As Michael rightly recognizes, however, the law cannot simply adopt a fiction as the basis of a justifiable moral system that inflicts pain on individuals. ${ }^{10}$ If we are not really responsible, we should not be blamed and punished as if we were. Moreover, "as if" responsibility cannot explain current criminal law doctrines or practices, wlich are essentially retrospectively evaluative. ${ }^{11}$ In sum, the hard determinist approach is no guide to the relation between results and desert.

Many people claim im contrast that determinism is false, or that it is so contestable that we need not accept its truth. ${ }^{12}$ But even if determinism or universal mechanism is false, the macro-world is so massively regular that it certainly behaves as if these hypotheses were true, and any moral theory must take account of this reality, what Galen Strawson calls the "Realism Constraint." ${ }^{13}$ As I have previously implied and will discuss below, the realism constraint applies as much to human action as to any other phenomiena.

The libertarian argues specifically that the law is right to reject mechanism as an explanation of human conduct. The libertarian is able thus to distinguish action from results because mechanism does not apply to human action, even if it does account for all the other phenomena of the universe. People are allegedly prime movers unmoved and thus responsible, at least if they are rational and not compelled in the ordinary sense of compulsion. In the libertarian view, human action is uncaused except by human intention and is thus not a matter of luck. The rest of the universe may or may not be causal, but all else is surely a matter of luck because only our actions are up to us. Thus, a plausible libertarian claim can be made that results should not matter and that actions are the only proper basis for assessing culpability.

Like Michael, I believe that libertarianism "border[s] on the unintelligible;"14 indeed, I believe that libertarianism is preposterous. Therefore, it cannot be a guide to why results should or should not matter, or to any other sensible legal conclusion. I fully agree with Michael's arguments against libertarianism as a plausible causal

10. See Moore, supra note 3, at 868-870.

11. See R. JAY Wallace, Responsibility and the Moral Sentiments 54-61 (1994).

12. Sandy Kadish raises this argument. See Kadish, supra note 6, at 690.

13. Galen Strawson, Consciousness, Free Will, and the Unimportance of Determinism, 32 INQUIRY 3, 12 (1989).

14. Moore, supra note 3, at 871 . 
metaphysics. The arguments that follow simply complement Michael's critical analysis of the libertarian solution to responsibility in general, and of why human action may be distinguished from results in particular. ${ }^{15}$

One form of libertarianism holds that human actions are the product of indeterministic events in the brain. But why should such events ground responsibility? In what way are they ours or an exercise of a freedom worth wanting? If rational action is simply a product of biophysical indeterminacy, no one should be responsible for any action. This form of libertarianism provides no sound view of the relation between results and deserts because its conclusion is nihilistic concerning responsibility-and, one might add, about our ability dependably to control our environment through action.

An apparently more plausible version of libertarianism concedes that prior events and experiences affect our mental states, but alleges that our actions are ultimately uncaused by anything other than ourselves. In addition to the inability of such a theory to specify the nature of the causal relation between an agent and an act that she causes, a point Michael rightly notes, ${ }^{16}$ there is no observational evidence that would confirm that agent causation is true. Why would we choose to adopt such an implausible theory when there are no good nonobservational grounds, such as coherence or parsimony, for doing so ? $^{17}$ Finally, our desire to believe that agent causation is true, or the intportance to our self-conception of this truth, is not a sufficiently good reason to accept that truth.

Even if agent causation were true, however, Hilary Bok has shown ${ }^{18}$ that this theory does not avoid the problems of mechanism. Suppose that mechanistic forces determined all our mental states and processes other than our intentions themselves, and suppose further that all these mental states and processes led inevitably to the intentions that we did form. Even if those intentions were somehow uncaused-an implausible assumptionthis form of agent causation would be essentially indistinguishable from mechanism. Nor would responsibility be more secure if agents somehow always formed intentions not to do what they had reason to do based on prior deliberation or if they acted for no reason at all, despite having good reasons for some course of action. Why would the freedom to choose a course of action that, all things considered, we thought we should reject, or to choose to act for no reason, be a freedom worth wanting? Why would we generally want to act intentionally for no good reason? So, if we always acted in accord with the reasons we were caused to have, the substance of our actions would be determined, even if the ultiniate intention to act was

\footnotetext{
15. See id. at $871-872$.

16. See id. at 871.

17. See Hilary BoK, Freedom ANd Responsibility 45 (1998).

18. See id. at $48-50$.
} 
somehow uncaused. And if we acted for no good reason that we credited, this freedom of action would be undesirable because it would not involve independent, rational evaluation of what we had reason to do.

Finally, suppose a libertarian concedes, as one rationally must, that preceding events and conditions do affect our mental states and processes, and thus also our reasons for action. In that case, external causal processes would not determine the agent's actions only if some aspect of the agent evaluates reasons for action independently of the reasons the external world causes the agent to have. ${ }^{19}$ But then the agent would not be aware of the aspect of the agent that is performing the independent evaluation. If causal forces are causing me to see the world a certain way and to have certain reasons for action, then I will not try to question that understanding or those reasons, because I have no reason to do so. An independent, evaluating aspect of the self is not identical to the conscious, intentional agent because that agent would not be aware of any reason to evaluate its reasons independently of those it was already determined to have.

If there is an aspect of the agent able to cause the agent to see the world differently and to have reasons for action different from those that external causal processes produce, that aspect of the agent must be able to override the reasons that external causes produce and that the agent consciously has. But then an agent's reasons for action are being controlled by an aspect of the agent of which the agent is unaware and with which the conscious, intentional agent does not identify. This nonconscious aspect of the agent is thus controlling the agent's reasons for action as much as external forces ever did. The saine threat to moral responsibility obtains as if mechanism were entirely true. And, finally, we are entitled to ask the libertarian why the independently evaluating aspect of the self is uninfluenced by preceding events and how it comes to have contra-causal power. In suin, even if our intentions are not determined by external causal processes, libertarians must concede that they are nonetheless causally determined by processes over which conscious agents, acting selves, have no control. Consequently, on this version of libertarianism, too, human action and results are equally the product of causal forces.

In conclusion, neither hard determinism nor libertarianism can provide a desert-based justification for why results should (or should not) matter. Hard determinism has no genuine concept of desert. Moreover, there is no a priori reason to think a consequentially sound legal causation doctrine will map the actual metaphysics of causation. Libertarianism, even if it is plausible metaphysically, fails adequately to distinguish between allegedly free action and lucky results.

19. I owe this argument entirely to Hilary Bok. See id. at 48-50. 


\section{B. Compatibilism}

The compatibilist answer to the argument that mechanism and moral responsibility are inconsistent is to claim that mechanism is both true and compatible with moral responsibility. This answer in its various forms is dominant today among moral philosophers ${ }^{20}$ and is the approach that both Michael and I adopt. ${ }^{21}$ This approach accepts completely that we live in a thoroughly causal world, at least at the macro level, and that causal processes produce human action and all the other phenomena of the universe, but it also holds that genuine responsibility is possible. Moreover, this approach best explains and justifies our moral and criminal law practices without endorsing the baroque implausibilities of libertarianism. Even if mechanism is true, the law's concepts of moral responsibility and deserved blame and punishment are rationally defensible on this view. Defending this position goes far beyond the goals of this Response, but I believe that any analysis of why results matter to desert, including Michael's, should proceed not in response to current attitudes and doctrine, but from the standpoint of the compatibilist theory of responsibility and desert. It is conceivable to me that some compatibilist view might imply that results matter to desert. I suggest, however, that the compatibilist view that both Michael and I hold is inconsistent with the conclusion that results matter.

A compatibilist holds an agent responsible if the agent acts intentionally, complies with or breaches a moral or legal obligation we accept, and the agent is generally capable of grasping and of being guided by reason in the context. ${ }^{22}$ If these conditions are met, praise and reward or blame and punishment are morally justified. For the compatibilist, moral responsibility is dependent primarily on the agent's general capacity to grasp and be guided by reason, because it is reasonable and fair to hold an agent responsible only if the agent possesses this capacity. According to this account, human action is different from the rest of the causal universe not because it is uncaused, but rather because it is the product of potentially rational practical reason. Only people act for reasons, and moral and legal rules are thus action-guiding primarily because they provide an agent with good reasons for forbearance or action.

It follows from the compatibilist account that results do not matter for the following reason. Reason cannot fully affect an agent's causal background, opportunity set, or the physical events of the universe. We can use reason to try to modify our characters or desires, but this is notoriously

20. See, e.g., BoK, supra note 17; John MARTIN FISCHER \& MARK RAVIZZA, ResponsibiLitY AND CONTROL: A THEORY OF MORAL RESPONSIBILITY (1998); WALLACE, supra note 11.

21. See Michael S. Moore, Causation and the Excuses, 73 CALIF. L. Rev. 1091 (1985); Stephen J. Morse, Excusing and the New Excuse Defenses, in 23 CRIME AND JustiCE: A Review of RESEARCH 329, 337-62 (Michael Tonry ed., 1998).

22. See Wallace, supra note 11 , at $86-87,157-61$. 
difficult to do. Desires are often brute and unbidden, and character traits can be supremely impervious to change. At most, we can nibble at the margins. Character and desire are not primarily a product of our reason. We can, of course, use reason to guide us towards benign environments and away from those that would tempt us to evil, but even the greatest caution and foresight will not prevent an appointment in Samarra. ${ }^{23}$ Again, opportunity is not primarily a product of reason. Finally, we can use reason to predict the consequences of various actions and thus to decide which to perform, but even the greatest degree of knowledge and attention will not prevent the forces of nature, including other human actions, from sometimes intervening to prevent (or to complete in unpredictable ways) the utterly predictable, natural, and probable consequences of our actions (or nonactions). Our reason plays no role in those forces. In the entire causal chain that leads to the compliance with or breach of moral and legal obhgations, the capacity for reason fully explains only the reasons for action that cause agents to act intentionally. This, finally, is why culpability depends ultimately on action and not on character, desire, opportunity, or results. We are culpable only for action because only action is guided by reason, not because only action is free of the causal processes of the universe.

Michael Moore agrees that culpability depends entirely on action, but holds also that wrongdoing independently contributes to desert. In Placing Blame ${ }^{24}$ he provides an extensive moral argument for this conclusion. Answering that argument in detail would require a paper in itself-a task in which I am currently engaged..$^{25}$ For now, however, let me simply make a few brief remarks to indicate why I find this position implausible. First, much of Michael's argument depends on our preexisting attitudes and practices. He believes that he can avoid circularity or trivial noncircularity, but I do not think he succeeds. If I am right, then his argument is really about sociology or "policy" and not about moral justification, a strategy he explicitly rejects in his current Essay. ${ }^{26}$

More important, the equation of wrongdoing with actual harm is unpersuasive. No acceptable moral or political theory holds that people have an absolute right to a risk-free environment. Accidents will inevitably occur, and people will be harmed, even if everyone is always reasonably careful. The realism constraint teaches us what results we can reasonably expect to follow from our actions, but even in the clearest cases we can never be sure because we can never fully control the world around us. At

23. See Terry Pratchett, The Colour of Magic (visited Feb. 8, 2000) łttp://www.demon. Ispace.org/books/apf/the-colour-of-magic.html> (discussing the origins of the allegory of Samarra).

24. See MoORE, supra note 1, at 218-46.

25. See Stephen J. Morse, Guiding Goodness (in progress) (unpublished manuscript, on file with author).

26. See Moore, supra note 3 , at 828,868 . 
most, all we can ask of each other is that none of us should intentionally place fellow citizens unreasonably at risk of harm. Doing so constitutes at that moment a breach of the duties the agent owes to the person or class of persons who might be harmed by the agent's action under the circumstances, and the degree of breach is dependent on the mental state with which the agent acted. For example, intentionally creating the risk of harm with the intention that it occur is more culpable than intentionally creating a risk of harm but without the intent that it should occur. ${ }^{27}$ No victim is necessarily harmed by a breach, but the potential for the harm the breach threatens is complete at the moment the agent acts to create the potential for harm. Thus, the potential victim or class of victims is fully wronged at the moment of the breach, because that is when the victim's rights are fully violated.

Moral and legal rules ultimately aim to prevent harms, of course. Risking harm constitutes a breach precisely because harm is risked. But there is no further wrong, no further violation once the agent acts wrongfully to put a victim at risk. There is surely the possibility for harm, but the amount of harm ultimately caused adds nothing to the wrongfulness of the agent's conduct, the violation of the duty owed to the potential victim. At most, the harm actually caused has epistemic value as a guide to the agent's intentions. Potential victims and society are wronged by wrongful action, even if no harm ensues: Thus we have laws punishing (even unsuccessful) attempts. In contrast, even the greatest harms are not wrongs unless the agent breached a duty by creating an unreasonable risk. Accidental death is the clearest example. It is possible, of course, that morality might not be symmetrical here. The amount of harm might contribute to desert when an agent breaches a duty, but not when an agent acts entirely innocently. It is true as a matter of sociological observation that we tend to suspend reactive attitudes of anger and resentment when we believe that a harmdoer acted innocently and that our reactive attitudes to breach are in fact proportionate to the amount of harm done. But again, this is a bit of sociology, not moral justification.

Moral and legal rules are action-guiding, at least in large part, and thus they are concerned with reasons for action. Why, then, should moral condemnation and desert and punishment apply to phenomena beyond the reach of reason? Results are properly objects of celebration and regret, but only actions should be objects of moral praise or blame. ${ }^{28}$ For

27. Cf. Larry Alexander, Insufficient Concern: A Unified Conception of Criminal Culpability, 88 CALIF. L. REv. 931 (2000) (arguing that purpose and knowledge can be collapsed into recklessness and that negligence should not be a culpable mens rea and cannot be distinguished from strict liability).

28. I recognize that many people think that people deserve to be rewarded for luckily causing good results. For example, many believe that scientists deserve to be rewarded for the lucky outcomes of their investigations, even if the good result is the product of flawed rcasoning and methods. For various reasons concerning incentives and the like, we may wish to reward lucky good results, but for 
compatibilists such as Michael and me, the universe is fully causal. But results should not matter to desert, and therefore causation should not either. Our knowledge of how the world causally works should enter responsibility assessment only by guiding judgments about the type of harm an agent's intentional conduct risked.

II

\section{The Unlikely Metaphysics of Legal Causation}

\section{A. The Seamlessness of Causation}

The metaphysics of causation is essentially contested terrain, with positions taken that range from skepticism to realism. For example, Michael recognizes that the proposition that causation is scalar, which is central to his metaphysics of causation, is controversial..$^{29}$ If the moral justification for legal causation doctrine requires convincing understanding of the metaphysics of causation, it is unlikely in the extreme that at present such a justification is imminent. This is especially so because, to the best of my knowledge, few theorists other than Michael are working on the metaphysics of legal causation. My introduction suggested that this aspect of metaphysics in particular is conceptually suspect, and I suspect that the paucity of work in this area reflects the recognition that investigating the metaphysics of legal causation is probably fruitless, even with increased understanding of the metaphysics of causation in general. The contested state of the metaphysics of causation is arguably contingent, however, so let me say why I believe the project cannot succeed.

Let us begin with the assumption that we can make some rough sense of the notions of cause and causation. That is, causation is not simply the observation of regular relations between precedent and subsequent events. Let us suppose further, as Michael sensibly does, that we live in a causal world or at least in a universe sufficiently subject to mechanism to satisfy the reality constraint. This universe had a beginning, which for convenience we may call the Big Bang, after which the causal laws operated on those states and events existing at the inception. All subsequent states and events were then caused to occur, according to the covering causal laws. The best understanding of this state of affairs is that causation is a seamless web. Viewed from the Big Bang forward, there are no gaps or sharp breaks in causation. ${ }^{30}$ It is surely true that we experience existence as if there were, but causation does not stop anywhere. Like Old Man River, causation just keeps rolling along.

the reasons given in this Response, I believe such rewards are not genuinely deserved unless they were intended in the appropriate way.

29. See Moore, supra note 3, at 874-875, 874 n. 229.

30. See Tyler Burge, Mind-Body Causation and Explanatory Practice, in Mental Causation 97, 102 (John Heil \& Alfred Mele eds., 1993). 
When a harm occurs and we are motivated to search for causes, we trace backwards along the causal chain, searching for a cause to which we can fairly attribute liability. Given sufficient information, we can say with great confidence that an event would not have occurred but for some prior event or state, or that more than one concurrent cause was a sufficient actual cause although none was necessary. We do identify stopping points based on common sense or social and legal purposes, but the complete causal story for any event goes back to the beginning in a web of infinite complexity. Indeed, as products of pure physical causation governed by the covering laws of the universe, all causes are metaphysically homogeneous, and there is no apparently natural, nonarbitrary stopping point. Indeed, there are no accidents in nature, an insight celebrated by the plaintiffs' bar. No cause ever "interferes" with the natural course of events because all courses of events are entirely natural. It is metaphysically unlikely in the extreme that there are sharp breaks or gaps in the causal web of the universe or that causation "peters out." Nature is almost certainly not carved at the joints this way.

Recognition of the apparently seamless nature of physical causation motivates the libertarian argument, because if human intentions are uncaused, then they are a natural stopping point. The usual compatibilist answer is that human intentions are the product or potentially the product of reason, and that differentiates them from other causes. This is true as a description, but it is hard to see why, in terms of the mechanism of causation, reason distinguishes intentions from other phenomena that are equally the products of mechanism. In a mechanistic universe, causal processes produce reasons as well as all the other products of mechanism. Now there are many compatibilist answers to this conundrum ${ }^{31}$-although none is fully satisfying to a libertarian - but none even attempts to deny that all events are metaphysically homogeneous as the product of mechanistic physical causes. Intentions are different from other phenomena, of course, in the same way that bacteria are different from people, but all phenomena are the end products of mechanistic causation.

I wish to be clear that my claim-that metaphysically there are no natural, nonarbitrary stopping points in the web of causation beginning with the Big Bang-is entirely consistent with the claims that there are causal laws, that common sense and science allow us to discover those laws, and that we can use these laws to understand and to manipulate the world to achieve our ends. For example, we do act intentionally and often successfully to cause changes in the course of events that would have occurred but for our actions. Our understanding of the physical causal world is of course crucial to that success. Accepting mechanism does not entail fatalism, which is the view, roughly, that our intentions and actions

31. See sources cited supra notes 20-21. 
do not affect the world. We also understand that even with sound knowledge of causal laws, we often have limited ability to control and predict the future course of events that we try to set in motion. Despite our intentions, unpredictable natural events or human actions may prevent (or complete unpredictably) the results we intended and, ex ante, had every reason to expect would occur in the manner we expected. The actions of ourselves and others and natural events are of course part of the causal explanation of what in fact happens, and we can identify and employ such acts or events for legal, moral, social, and scientific purposes. But once again, metaphysically, causally there are no gaps, no coincidences, no interferences. Causation is all one seamless, metaphysically homogeneous web.

The criminal law distinguishes between actual, usually but-for, causes and proximate causes, but it must be remembered that the original agent who set the chain of causation in motion is a but-for cause, whether or not the causal chain is legally "cut" by a later natural event or human intervention. It is crucial to remember that the legal chain is cut, but not the natural one. That is, both the original agent and the later natural event or human action are all part of the complete chain of causation of the ultimate harm. Whether or not we hold an agent responsible for a result in a chain of causation that includes the agent's intentional act, there are no genuine causal gaps. The law indulges the obvious fiction that the causal chain is cut only because its own good and various policy considerations seem to create the need for this outcome, but metaphysically, a so-called coincidence or an intentional, wrongful human action is a cause like any other. Indeed, if we described causes at different levels of generality, or if we had better information, coincidences would hardly seem coincidental. Now Michael is surely right that the original agent's moral culpability is not one of those policy considerations that properly indicates where to cut off liability. After all, the agent's culpability is complete at the noment of action and cannot affect what events occur thereafter. But other policy considerations, and not nature, dictate the legal cut points for liability.

\section{B. The Futility of a Metaphysics of Legal Causation}

Suppose we assume the metaphysically implausible scenario that there are gaps, breaks, and peterings-out in the umverse's chains of causation. If so, it is even more implausible that legal categories of proximate causation map them precisely. First, although the causal laws establishing the production of gaps, breaks, and peterings were in place from the inception of the physical universe, waiting to be discovered, most of the doctrines of legal causation were developed by common lawyers lacking the most rudimentary understanding of actual causal processes or of the philosophy of science and causation. At best, they were using ordinary com- 
monsense notions of causation that are rough and ready but necessary aids to practical deliberation in a causal world. Moreover, these doctrines were developed in response to practical questions of liability, not as a priori speculations about the metaphysics of causation. Even for those enamored of the genius of the common law, it beggars the imagination to think that common law lawyers implicitly developed legal proximate cause doctrines that are congruent with the extant metaphysics of causation.

More important, the history of legal causation doctrine tells a story of such vague doctrines responding to such complex occurrences that it is literally incomprehensible that those doctrines would map metaphysical causal reality. The cases tell stories of deviant, wacky, unpredictable, and complex causation that are beyond even the infimitely fertile reaches of Leo Katz's hypotheticals. ${ }^{32}$ Common law lawyers were and are constantly forced to stretch or modify arguments and doctrines to encompass new sets of facts that challenge the established categories, but the process was and is never-ending, despite the ingenuity of the lawyers. The difficulty of the process explains why lawyers ultimately have had to accept exceptionally vague, indeterminate causation criteria. The difficulty also explains why even the most ingemous attempts to reconstruct a rational, underlying theory, such as Michael's, are always unstable, open to numerous counterexamples or counterarguments, lapse into ad hoc explanation, grasp for counterintuitive categories, such as "aiding nature," and ultimately produce problems of their own. ${ }^{33}$

It is fair to claim that the best explanation of current causation doctrines is legal policy, especially the concern that some harms simply seem to the average person "too remote" 34 to be a fair basis for ascribing liability for results to the initial but-for agent. For example, the law increasingly fails to break the causal chain when highly predictable human intervention, such as the reckless driving of a co-drag racer, occurs. ${ }^{35}$ No new discoveries about the metaphysics of causation dictated the result that the original drag racer was indeed a cause, much as no new evidence about psychopathology, psychophysiology, or anatomy caused the American Psychiatric Association to declare in 1973 that homosexuality per se was no longer a

32. See generally Leo Katz, ILL-GotTEn Gains: Evasion, Blackmail, Fraud ANd KINDREd Puzzles of THE LAW (1996); Leo Katz, Why the Successful Assassin Is More Wicked than the Unsuccessful One, 88 CALIF. L. REv. 791 (2000).

33. See Stephen Perry, Moore on Causation (Feb. 10, 1999) (unpublished manuscript, on file with author) (commenting on Moore's analysis of causation doctrine as seen in Moore, supra note 5).

34. "[T]oo remote" is the Model Penal Code's criterion for limiting liability. See ModeL PeNAL CODE $\$ 2.03(2)(b)(1962)$.

35. See, e.g., State v. McFadden, 320 N.W.2d 608 (Towa 1982). The example is of course drawn from Sandy Kadish's massively influential casebook. See SANFORD H. KADISH \& STEPHEN J. Schulhofer, Criminal law aNd ITs Processes 575 (6th ed. 1995). 
disease. ${ }^{36}$ Policy dictated both results. Indeed, I hypothesize that no "discovery" about the metaphysics of causation ever affects legal doctrine, although scientific discoveries about actual causes do affect specific liability claims. It would be an extravagantly lucky event, an exceptionally happy and comforting coincidence, if legal causation doctrine mapped preexisting causal metaphysics. Why, therefore, should we assume that we should try to find a prelegal notion of causation to justify a set of doctrines constructed to serve other purposes? Why assume current doctrines are the data to be explained by the prelegal notion? With ceaseless jiggering to make the prelegal and legal notions cohere, will we not be engaging in an essentially circular enterprise? If causation morally matters at all, should we not start instead with a priori metaphysical truths about causation and then construct our legal doctrines accordingly?

Even with such truths of theoretical reason in hand, no particular normative legal policy will follow. I am not denying that discoverable facts about the metaphysics of causation will not or should not affect moral and legal policies; moral claims do supervene on natural properties. Nonetheless, no such discovery will necessitate any particular normative conclusion. If the metaphysics of causation is vastly more complex than the common sense conception of causation, as I suspect it is, it will command allegiance as a ground for assessing liability only if ordinary people can understand and apply it and if we can be convinced that using that metaphysics will contribute to human flourishing. But there is no a priori reason why this should be so. After all, there is no reason to believe that the physical universe cares about morality or is moral (or immoral). Believing that following the metaphysics of causation will contribute to human welfare will require a moral arguinent independent of the pure metaphysics of causation. If a convincing moral argument is not forthcoming, and the metaphysics of causation leads to legal results too different from the common sense of causal liability, theoretical reason will rightly be ignored. Finally, if a good theoretical argument to follow the metaphysics is produced, but once again the outconie differs too much from common beliefs about justice, theoretical reason will again be ignored for much the same psychological reasons that the commonsense belief that results matter is also inpervious to reason. Ingenious types will try valiantly to show that reason does support the rejection of a sound theoretical argument, that is, that the theoretical argument is not so sound after all. In short, the legal

36. See American Psychiatric Association, Position Statement on Homosexuality and Civil Rights (Dec. 15, 1973), reprinted in 131 AM. J. Psychiatry 497 (1974); Ronald Bayer, Homosexuality and American Psychiatry: The Politics of Diagnosis 101-54 (1981) (arguing that history indicates that morals and politics rather than novel and solid scientific findings motivated the Association's change in position). 
doctrines and practices we observe are the best of all possible worlds, albeit they may need a bit of tinkering.

Ultimately, much of Michael's metaphysical quest is driven by his realist moral metaphysics. Much as he believes that there is a truth about the metaphysics of causation that has existed from the inception of the universe, he also believes that there is a metaphysical moral truth that also has existed from the Big Bang forward. And to the extent that morality requires a theory of causation, the two should cohere to achieve a morally acceptable result. One need not be any kind of relativist about morals to reject this view, however. At the very least, no possible information or evidence could ever confirm it or disconfirm it. It simply adds a mysterious criterion to an already legally and morally overloaded explanatory apparatus. I am simply not convinced that we need a metaphysics of causation to justify the legal doctrine. Even assuming that results matter and that the agent's moral culpability has no effect on the causal chain, where we cut the chain is open to arguments about and criteria for maintaining the integrity of the criminal law and upholding the rough sense of justice that should be accepted by criminals, victims, and society at large. No more precise criteria should or could be forthcoming, and certainly they will not concern desert.

The failure of the common law to provide a clear, consistent theory of causation that might map the metaphysics of causation is not surprising. If causation doctrine is simply trying to satisfy a rough sense of justice with proximate cause doctrines, no one would expect that these doctrines would precisely map the metaphysical facts about mechanistic processes. There is no causal metaphysics of proximate causation. Although there might be a metaphysics of actual causation, there is no reason to believe that it will yield morally nonarbitrary, principled legal stopping points with which to ascribe desert. ${ }^{37}$ Drawing the metaphysical map of legal causation is beyond even the most insightful, profound moral Mercator. I would like nothing better than to play Dixon to Michael's Mason, but it cannot be done.

37. Once again, there might be nonarbitrary stopping points based on consequential goals, but not desert. 